\title{
ECONOMÍA AURÍFERA, CAMINOS Y FUERTES EN LA ARAUCANÍA (NGÜLÜMAPU) DEL SIGLO XVI: EN TORNO A LA INFORMACIÓN DE MARTÍN RUÍZ DE GAMBOA DE 1579*
}

\author{
GOLD ECONOMY, ROADS AND FORTS IN THE XVI CENTURY ARAUCANÍA \\ (NGÜLÜMAPU): ON THE 1579 INFORMATION OF MARTÍN RUÍZ DE GAMBOA
}

\author{
José Manuel Zavala Cepeda**, Tom D. Dillehay**** \\ y Francisco Javier Medianero Soto ${ }^{* * * *}$
}

\begin{abstract}
Tomando como hilo conductor la información enviada al virrey Toledo por Martín Ruíz de Gamboa en 1579, este artículo analiza la relación existente entre economía aurífera, estructuras poliorcéticas y vías de comunicación en La Araucanía (Ngülümapu) del siglo XVI. Se muestra la fragilidad del sistema de ocupación española, pero al mismo tiempo su gran extensión territorial y la operatividad de las vías de comunicación entre enclaves, puestos avanzadas, faenas mineras y asentamientos indígenas. Se trata de un modelo en que coexisten y se superponen economía de guerra y aurífera y donde la ocupación española se establece sobre la base de infraestructuras, poblaciones, recursos económicos e instituciones indígenas preexistentes a dicha ocupación.

Palabras claves: Araucanía siglo XVI, Minería Colonial, Fuertes siglo XVI, Martín Ruíz de Gamboa, Caminos Coloniales, Mapuche siglo XVI.
\end{abstract}

Taking as a thread the information sent to Viceroy Toledo by Martín Ruíz de Gamboa in 1579, this article analyzes the relationship between the gold economy, defensive structures and communication channels in the 16th-century Araucanía (Ngülümapu). The fragility of the Spanish occupation system is shown, but at the same time its great territorial extension and the operability of communication systems between enclaves, outposts, mining operations and indigenous settlements. It is a model in which the war and the gold economy coexist and overlap and where the Spanish occupation is established on the basis of infrastructure, populations, economic resources and indigenous institutions pre-existing to said occupation.

Key words: 16th century Araucanía, Colonial Mining, Forts 16th century, Martín Ruíz de Gamboa, Colonial Roads, 16th century Mapuche.

El objetivo que nos proponemos en este artículo es relacionar lo avanzado en el estudio de estructuras poliorcéticas ${ }^{1}$ de La Araucanía o Ngülümapu ${ }^{2}$ quinientista, los denominados "fuertes", con el funcionamiento de una economía aurífera regional, principalmente del área sur de este territorio, la cual incluía las jurisdicciones de las ciudades españolas de La Imperial, Villarrica y Valdivia.

Para este propósito, tomamos como fuente principal la información que envía al virrey Toledo en 1579, el teniente general y futuro gobernador de Chile (1580-1583) Martín Ruíz de Gamboa $^{3}$. La coyuntura en la cual escribe Ruíz de Gamboa es interesante porque se estaba cerrando un ciclo de alta productividad de los lavadores de oro chilenos con un pico de $945,6 \mathrm{~kg}$ en el año de
1575 (Cuadra y Arenas 2001: 65) y donde diversos indicios nos señalan que los placeres auríferos del sur de La Araucanía eran aquellos que estaban contribuyendo mayormente a esta productivi$\mathrm{dad}^{4}$. El mismo Ruíz de Gamboa menciona en su carta a los lavaderos de La Imperial como los más ricos del reino (AGI, Chile 31, Carta de Ruíz de Gamboa del 1 de abril de 1579, f. [5]).

$\mathrm{Si}$ bien nuestro interés de investigación principal se centra en la actividad aurífera, la complementariedad e interdependencia de temáticas que cruzan la precaria realidad de la colonización española del siglo XVI en el Ngülümapu, lo fragmentario de la documentación colonial temprana y la poca evidencia arqueológica que han dejado los lavaderos de oro (Zavala et al. 2020), nos impulsan a ampliar el campo de observación a otros

\footnotetext{
* Resultados del Proyecto Fondecyt Regular No 1170551, Tras la ruta del oro: los habitantes de La Araucanía frente a la ocupación española del siglo XVI, recepción, adaptación y resistencia.

** Universidad de Chile. Santiago, Chile. Correo electrónico: josezavala@uchile.cl.

*** Universidad de Vanderbilt. Nashville (Tennessee), Estados Unidos. Correo electrónico: tom.d.dillehay@ vanderbilt.edu.

*****Universidad Católica de Temuco. Temuco, Chile. Correo electrónico: javiermedianero@ gmail.com.
} 
aspectos que sin duda hacen parte de un mismo sistema de dominación colonial como son los sitios poliorcéticos, los caminos, las encomiendas y las guerras.

Nuestro trabajo se inscribe en una perspectiva interdisciplinar que trata de aportar una mirada más integral de los estudios coloniales a pesar del sesgo que indudablemente contamina una documentación histórica producida en un contexto de dominación colonial donde la voz indígena es completamente marginalizada, de ahí que recurramos a los datos arqueológicos y geográficos como una manera de contrastar las fuentes historiográficas. En este sentido, valoramos el trabajo que vienen realizando historiadoras/es mapuches (Marimán, Caniuqueo, Millalén y Levil, 2006; Comunidad de Historia Mapuche, 2013; Antileo, Cárcamo-Huenchante, Calfío, Huinca-Piutrin, 2015) para colocar en el centro de la escena histórica a quienes sufrieron y resistieron al colonialismo, proyecto que en particular para el periodo colonial temprano constituye un desafío metodológico importante debido a lo limitado y sesgado de las fuentes.

Con todo, cabe destacar investigaciones recientes que abordan de manera más integral el siglo XVI chileno, en particular respecto de la relación entre sociedad de conquista, economía aurífera, mano de obra indígena y desplazamientos forzados (entre otros, cabe mencionar: Inostroza, 2013, 2014; Contreras, 2016, 2017a y b, 2018; Valenzuela, 2017).

Para el caso específico del Ngülümapu queda aún mucho por hacer aunque una buena parte de fuentes primarias ya hayan sido publicadas. Por ejemplo, en los documentos de méritos y servicios publicados por José Toribio Medina (1888-1902, 1956-1963) e incluso en las crónicas tempranas más conocidas como las de Góngora Marmolejo (1862), Mariño de Lobero (1865) y Vivar (1966) hay datos dispersos que uniéndolos permiten reconstruir un panorama, limitado por cierto, pero más integral de situaciones vividas en los diferentes vericuetos del poder y en los espacios de interacción por individuos y colectivos de $\mathrm{La}$ Araucanía del siglo XVI.

\section{Los estudios sobre los denominados "fuertes" del siglo XVI}

La categoría "fuerte" se ha utilizado de manera muy amplia en Chile para designar diversos tipos de lugares con y sin edificaciones que presentan especiales condiciones defensivas o de visibilidad que los hacen particularmente aptos para fines militares aunque también puedan desempañar otras funciones como por ejemplo ser puntos de descanso o de vigilancia camineros (postas o tambos), lugares de refugio, puntos de control de faenas auríferas ${ }^{5}$, etc.

El estudio de sitios arqueológicos poliorcéticos en La Araucanía, ha estado particularmente centrado en la cuenca media y alta del río Toltén, primeramente, con relevantes aportaciones en la localización y documentación de sitios, en sus planimetrías y superficies y, más recientemente, con una visión de conjunto que integra sus rutas y caminos (Adán 2014; Gordon 1985; Harcha et al. 1999; Mera et al. 2004; Mera et al. 2015; Reyes 2004; Vidal el al. 1986).

Las dataciones de estos sitios los sitúan generalmente en el periodo hispánico temprano (segunda mitad del siglo XVI) pero también en el prehispánico tardío (Adán 2014; Gordon 1985; Harcha et al. 1999) con lo cual en este último caso se trata de estructuras propiamente indígenas previas a la conquista española.

Se sabe que las fortalezas españolas eran de forma cuadrada y triangular (Guarda 1990; Krumm 1974; Vidal et al. 1986), mientras que las formas circulares y ovales parecen asociarse a recintos defensivos indígenas (León 1986 y 19881989; Vidal et al. 1986).

Estudios arqueológicos han identificado una serie de "casas fortificadas" y asentamientos fortificados más pequeños que rodean el lago Villarrica y la ribera del río Toltén (Saavedra y Sanzana 1991; Vidal et al. 1986). Uno de estos sitios es el de Santa Sylvia, que probablemente fue ocupado por los españoles alrededor de 1585 por un corto período antes de ser abandonado y destruido (Gordon 2011; Sauer 2012). Estudios en Valdivia y sus alrededores apunta al mismo patrón de Villarrica (Adán et al. 2007; Adán et al. 2012; Urbina y Adán 2018).

Los fuertes indígenas prehispánicos probablemente se relacionen con conflictos armados entre grupos que compiten por tierras fértiles en procesos ligados a formas de vida más ancladas a ciertos hábitats, lo que desincentiva el alejamiento a pesar de las hostilidades. También, esto puede estar relacionado con estructuras identitarias fuertes que proporcionan marcos de referencia 
que permiten distinguir entre un "nosotros" y un "ellos"; el surgimiento de una elite política con intereses propios que crea rupturas internas; la invasión por fuerzas externas; la extracción de recursos preciados o las tensiones ecológicas producidas por sequías u otros eventos ambientales (como los señalados por Keeley 1996).

En la Figura 1 hemos geolocalizado las estructuras con vocación poliorcética del área sur de La Araucanía (términos de las antiguas ciudades de Imperial, Villarrica y Valdivia) independientemente de su atribución cronológica y cultural (indígena o hispana) a partir de la información proporcionada por la literatura arqueológica y etnohistórica, específicamente: Adán 2014; Adán et al. 2012; Archa et al. 1999; Gordon 1985 y 1991; Inostroza 1994; Inostroza et al. 2007; Mera et al. 2004, 2007 y 2015; Saavedra y Sanzana 1991; Sauer 2012 y Vidal et al. 1986.

El tipo de material cultural encontrado en algunos de estos recintos, no muy abundante por lo demás y principalmente indígena, indica la predominancia de la alfarería local, incluso en contexto de dominación española, lo cual tiende a fortalecer la idea de que el sustento demográfico principal de la conquista de las tierras mapuches era más bien de raigambre local y no foránea, es decir, la presencia de yanaconas $^{6}$ no sería dominante en estos espacios claramente asociados a la conquista española.

Coincidente con los trabajos arqueológicos mencionados, las crónicas y fuentes históricas refieren la existencia de este tipo de estructuras poliorcéticas españolas y también mapuche en el Ngülümapu: Mariño de Lovera 1865 [1595]: 351; Rosales1878 [1674]: 280; AGI, Chile, leg. 40; AGI, Patronato, legs. 29 y 187; AHNCh, MVM, vols. 273: f.82-83 y 274: f.132-138. El historiador Gabriel Guarda $(1978 ; 1990)$ ha sistematizado la información sobre los enclaves defensivos españoles del sur de Chile. Por su parte, Leonardo León (1986; 1988-1989) introdujo el tema de las fortificaciones indígenas como parte de una estrategia militar global, en particular en las zonas lacustres cordilleranas y precordilleranas entre el río Toltén y Osorno e Iván Inostroza $(2013 ; 2014)$

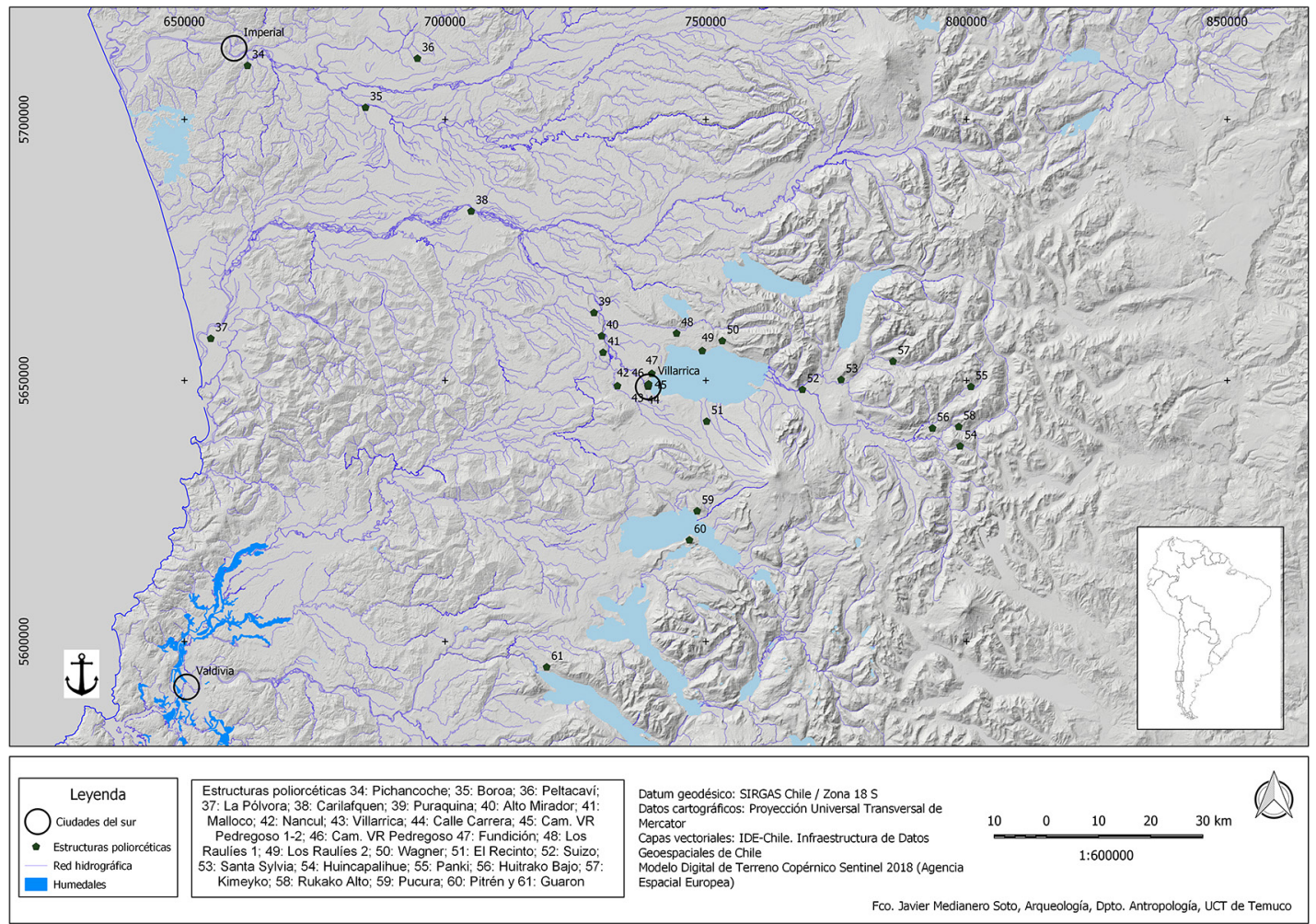

Figura 1. Estructuras poliorcéticas del área sur de La Araucanía. 
ha hecho aportes significativos sobre el área de influencia de la ciudad Imperial.

La ocupación española del Ngülümapu produjo ciclos de violencia y ofensivas indígenas anticoloniales, pero también conflictos internos entre segmentos nativos, unos aliados de los españoles y otros opuestos. Los hispanos trataron de asentar su dominio a través del régimen de encomiendas con el fin de contar con la mano de obra necesaria en los lavaderos de oro - principal razón de su presencia - así como en otras actividades productivas, domésticas y militares.

\section{Las vías de comunicación al momento de la conquista española}

El estudio de los caminos y otras vías de comunicación fluviales y marítimas no es un tema que haya interesado mucho a los historiadores del periodo colonial chileno. Sin embargo, para poder entender las dinámicas y procesos que tuvieron lugar en el continente americano, como en cualquier otro lugar y tiempo, es fundamental entender las formas y evoluciones de los desplazamientos y circulación de las personas, animales y cosas. Es por ello que en este apartado nos referiremos a las vías de comunicación y a los puntos de articulación multimodales (por ejemplo, los puertos) que utilizaron los españoles al momento de tomar contacto con el territorio araucano, pues, más allá de la relevancia que pueda tener el proceso de avance español hacia el sur, esto nos habla de sistemas de comunicación preexistentes y de dinámicas de movilidad que tiene un origen anterior a la llegada de los conquistadores europeos.

En efecto, el poblamiento español que se concretiza con la fundación de ciudades requería como condición necesaria que las urbes recién fundadas quedaran -al menos en una primera etapa- conectadas con la ciudad-base desde la cual provenía el frente colonizador, establecimiento que servía entonces de retaguardia y fuente de aprovisionamiento.

Para el caso de La Araucanía, la plataforma inicial del primer periodo fundacional (15511553) fue la ciudad-puerto de Concepción, fundada en 1550. Esto significa que los españoles debieron contar desde el principio con una buena conexión entre Concepción y las nuevas ciudades de "Arriba". En consecuencia, sin la preexistencia de caminos transitables que conectaran el frente de conquista con la retaguardia, la sustentación de las ciudades araucanas hubiera sido inviable, tanto como lo hubiera sido el no contar con un lugar seguro para establecer un puerto que permitiera a los territorios recién conquistados exportar e importar y ligarse marítimamente con la red comercial y político-administrativa más inmediata del virreinato del Perú ${ }^{8}$. Ese nuevo puerto fue Valdivia (1552) para el área situada principalmente del río Imperial al sur, en tanto que, para el área norte, continuó siéndolo Concepción. En la Figura 2 representamos, a grandes líneas y de manera aproximativa, las rutas terrestres y marítimas que ligaban las ciudades españolas del sur de Chile en el siglo XVI.

La preexistencia de una buena conectividad terrestre parece ser una explicación lógica a la rapidez de la ola fundacional de Pedro de Valdivia, quien tan solo en dos años fundó cuatro ciudades en el Ngülümapu: Imperial (1551), Valdivia (1552), Villarrica (1552) y Angol (1553). En efecto, se requerían unas vías de comunicación expeditas para el desplazamiento de personas, animales y mercancías que los nuevos enclaves españoles y la puesta en marcha de los lavaderos de oro necesitaban. Es posible reconstruir lo esencial de esa red siguiendo los pasos de Pedro de Valdivia detalladamente descritos por el cronista Góngora Marmolejo (1862 [1575]) ${ }^{9}$.

\section{La situación del sur de La Araucanía en la información de Ruíz de Gamboa}

El primero de abril de 1579 Martín Ruíz de Gamboa, envía su informe al Virrey Toledo sobre la situación de las ciudades del sur y la presencia del corsario Francis Drake en sus costas (AGI, Chile 31, Carta de Ruíz de Gamboa del 1 de abril de 1579, s./f.]). En esta relación, el teniente general, entrega detalles sobre los sistemas de comunicación que están operando entre las ciudades de la Imperial, Villarrica y Valdivia; da cuenta de los conflictos y alianzas con las poblaciones indígenas; informa sobre las explotaciones auríferas y menciona los fuertes y parapetos usados por indígenas y españoles.

Parte de los acontecimientos que relata Ruíz de Gamboa ya han sido analizados por Leonardo León (1988-1989), pero desde una óptica de historia político-militar diferente a la que estamos proponiendo ${ }^{10}$. 


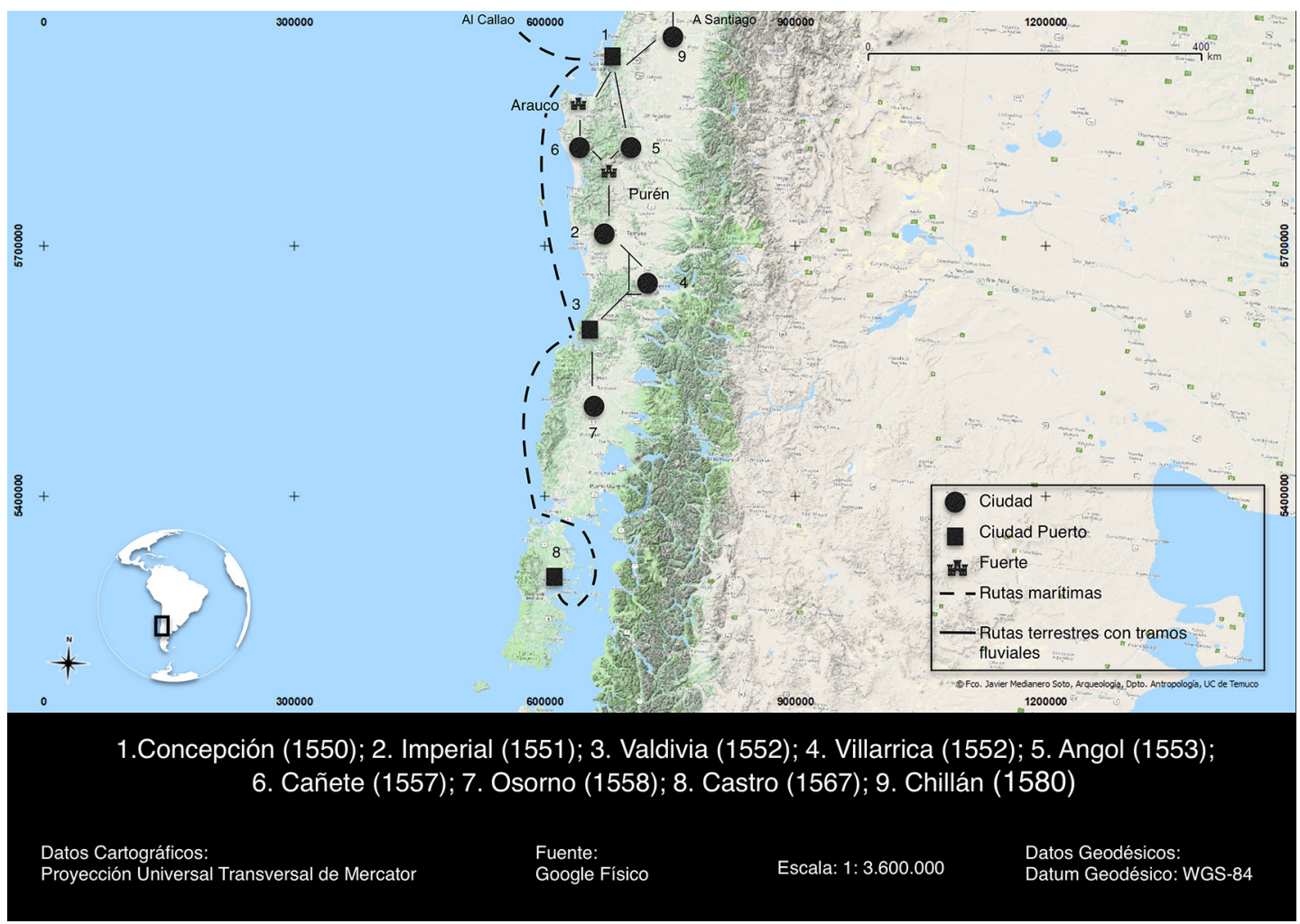

Figura 2. Rutas terrestres y marítimas de La Araucanía, siglo XVI.

\subsection{Indios "amigos" versus indios "enemigos"}

Los hechos relatados por Gamboa, dan cuenta de un momento en que la actividad aurífera está operando en la zona con altos y bajos, con tensiones y conflictos. Una parte importante de la población local está repartida en encomiendas y es destinada a la extracción de oro, esto provoca resistencias que a veces llegan a la rebelión abierta, de allí surge la particularidad designativa del autor del documento que distingue entre indios "de guerra" o "enemigos" e indios "de paz" o "amigos", con la cual diferencia aquellos que están en rebelión abierta de aquellos que continúan trabajando o apoyan militarmente a los españoles, pero en ambos casos se trata de indígenas encomendados, es decir que en algún momento fueron asignados a un encomendero como mano de obra, así lo señala Ruíz de Gamboa cuando dice:

[...] dexando el pasar de la cordillera comenzé de nuevo a hacer la guerra en la cordillera en los alzados que estaban encomendados mandando alzar los ganados i bastimentos [...]" (AGI, Chile 31, Carta de Ruíz de Gamboa del 1 de abril de 1579, f- [2]. [El destacado en nuestro]).

Ahora bien, al formar parte los indios de "guerra" de aquellos que habían sido encomendados, es de suponer que se trata de grupos que comparten con los de "paz" las mismas características que permitieron a los españoles someterlos a esta forma de trabajo o intentar hacerlo: es decir hacen parte de comunidades agrícolas muy arraigadas territorialmente que podían garantizar un nivel suficiente de productividad como para reproducirse y al mismo tiempo proveer de alimentos o mano de obra a los españoles. Comparten estructuras políticas cuyos niveles de agrupamiento superan las simples unidades de residencia pues existen conglomerados territoriales amplios, los Levo $^{11}$, y niveles diferenciados de autoridad, lo que se evidencia, por ejemplo, en la distinción que se establece entre simples caciques y caciques principales. 
Dicho lo anterior, el documento que estamos analizando -como muchos otros de la época-presenta a los indios de "guerra" como enemigos y en continuo combate con de los de "paz", a pesar de que ambos grupos comparten un mismo universo sociocultural y territorio. A este respecto, conviene tener presente tres cosas: primero, que la estrategia de conquista española se basó en explotar las disensiones internas; segundo, que la fuerza principal y más numerosas con que contaron los hispanos en los combates fue la indígena y, tercero, que las alianzas y sumisiones militares de los indígenas hacia los españoles siempre fueron frágiles y en cualquier momento podían deshacerse, de ahí la necesidad española de cortar de raíz cualquier rebelión para evitar que los "amigos" se convirtieran en "enemigos"12.

\subsection{Circuitos de comunicación, lavaderos y conflictos}

Veamos ahora los circuitos de comunicación y tránsito entre las ciudades de La Imperial, Villarrica y Valdivia y las diversas estrategias defensivas y ofensivas de españoles y mapuche.

Tanto en el sistema productivo como en las acciones de resistencia indígena y represión española, las tres ciudades, Imperial, Villarrica y Valdivia, figuran interconectadas.

En primer lugar, Valdivia en tanto ciudad puerto era el principal punto de nexo marítimo con el mundo para estas ciudades, por ello no es casualidad que funcionara en ella durante este periodo una Caja Real que recogía impuestos y financiaba gastos de las ciudades del sur (AGI, Contaduría, leg.1851, Cuentas de los Tesoreros de la ciudad de Valdivia, Francisco de Niebla y Francisco de Castañeda, 1574 a 1578). Siendo Valdivia sede de tributación (a lo menos en este cuatrienio), figura entonces como principal depósito de la hacienda pública de La Araucanía, lo que significa que allí convergía el oro que se producía oficialmente en la región para ser quintado y luego, cuando los ingresos fiscales eran superiores a los egresos, exportado a Lima y desde allí, probablemente a España, si es que no se destinara a otros gastos públicos del virreinato del Perú.

La localización de Valdivia, protegida por un intrincado sistema de islas, situada al interior de un estuario y rodeada de bosques con buena madera, la hacían un buen astillero y un puerto de los más seguro de las costas chilenas, dependiente directamente de Lima hasta mediados del siglo XVIII (Urbina y Adán 2014: 36).

Desde el puerto valdiviano, a fines del invierno de 1578, el teniente general Ruíz de Gamboa tomaba con su gente el camino a la Imperial para unirse al campo del gobernador que se encontraba estacionado allí, sin embargo, en curso de ruta, se desvía hacia Villarrica para auxiliar al corregidor de esta ciudad, Gaspar Verdugo, quien estaba siendo atacado en un "asiento" que había hecho con cuarenta soldados en un gran llano, a tres leguas del pueblo. Luego de dejar Villarrica bajo control, Ruíz de Gamboa retoma el viaje a la Imperial para -dos semanas más tarde- retornar a Villarrica con más refuerzos. Desde la ciudad lacustre, el teniente general inicia una campaña contra los "rebeldes" de los territorios lacustre-andinos situados frente a Valdivia (en torno al lago Riñihue); la importancia que el jefe español da a esta operación militar estaba en directa relación con el control de los lavaderos de oro de Villarrica. En la Figura 3 representamos los diversos trayectos del itinerario seguido por Martín Ruíz de Gamboa en estas campañas contra los indios enemigos del área lacustre, la reconstrucción de estos circuitos se ha hecho con base en criterios y algoritmos del Sistema de Información Geográfica (SIG) complementados con información de las fuentes históricas. Si comparamos esta Figura 3 con la siguiente Figura 4 que geolocaliza los placeres auríferos del área, se puede observar la coincidencia existente entre los sectores recorridos por el teniente general y la ubicación de los yacimientos mineros.

En efecto, por la localización de los acontecimientos, es probable que los lavaderos de oro de Madre de Dios, uno de los más productivos centros auríferos de Chile a partir de 1560 (Cuadra y Arenas, 2001), tradicionalmente asociados a la ciudad de Valdivia, estén entre aquellos que podían verse afectados por la rebelión y, seguramente, eran uno de los destinos a donde se obligaba acudir a los trabajadores de los repartimientos que estaban en rebeldía. Los otros lavaderos de Villarrica se distribuían con toda probabilidad por un extenso perímetro en torno al lago homónimo y más hacia los Andes, como por ejemplo en Liucura ${ }^{13}$, en la actual comuna de Pucón. En la Figura 4 se geolocalizan los 


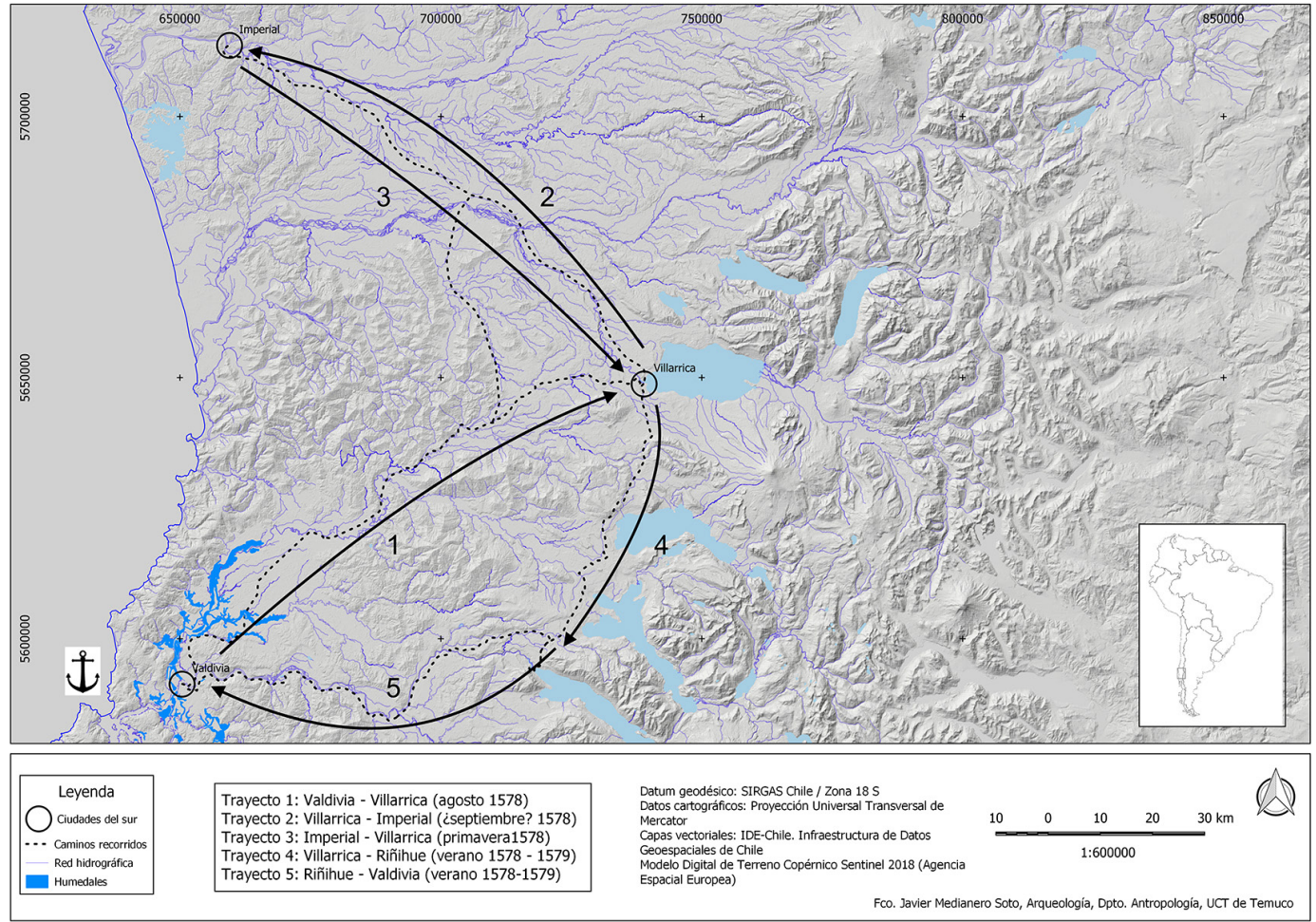

Figura 3. Itinerarios de Martín Ruíz de Gamboa en su campaña militar al área lacustre del sur de La Araucanía, 1578-1579.

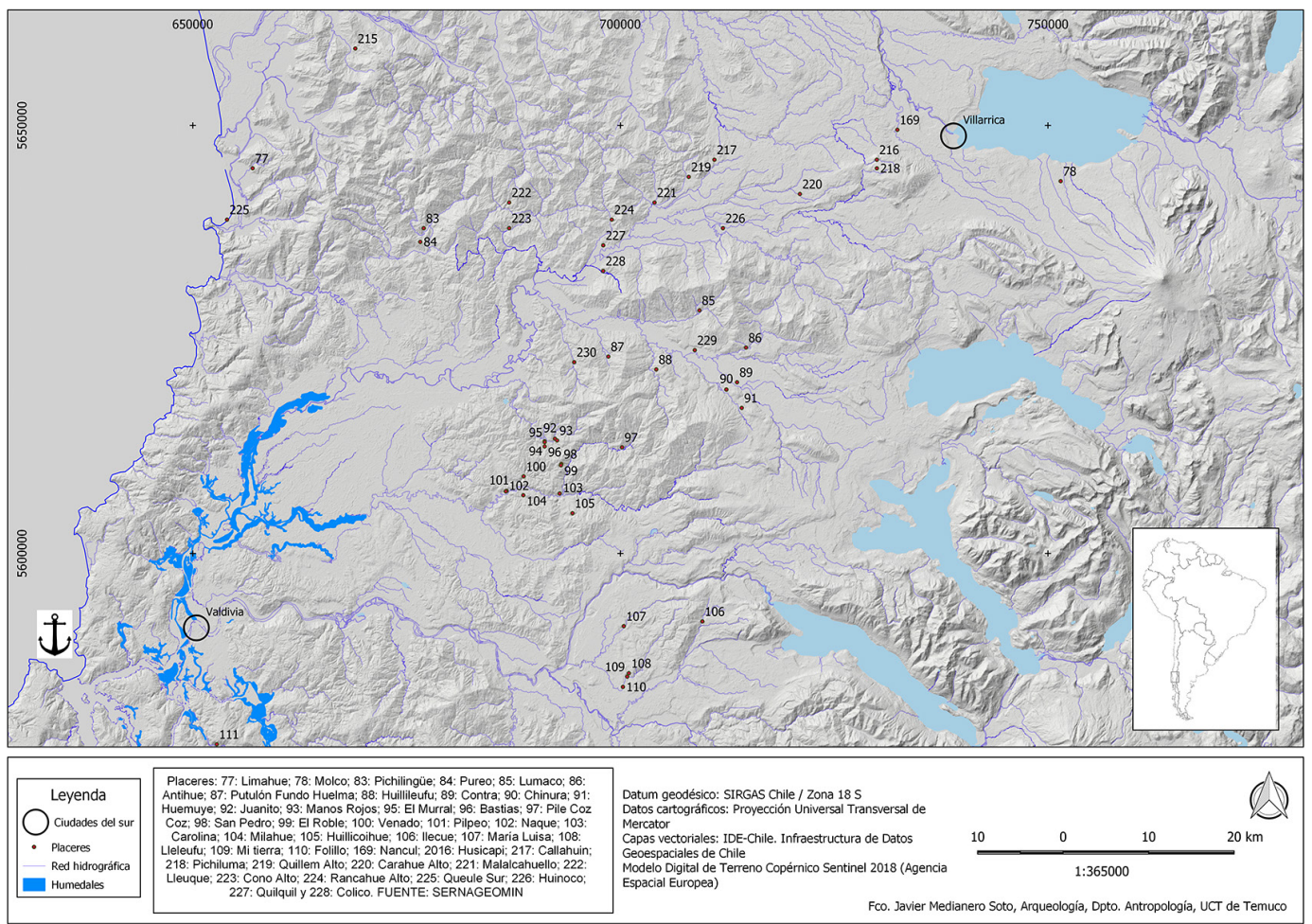

Figura 4. Placeres auríferos de Villarrica y Valdivia (Madre de Dios). 
placeres auríferos registrados por Sernageomin en el área de Imperia, Villarrica y Valdivia con independencia de su asignación cronológica y su grado de explotación.

Fueron dos columnas las que tomaron el camino al lago Riñihue ${ }^{14}$ desde Villarrica (ver Figura 3) hacia principios del verano de 1578 para sofocar a los rebeldes, una a cargo del capitán Juan de Matienzo con ochenta soldados y otra a cargo del mismo Ruíz de Gamboa con otros noventa, más las fuerzas de indios amigos que -aunque raramente se contabilizan- estaban siempre presente en las campañas y generalmente triplicaban o cuadruplicaban la cantidad de combatientes españoles.

Ambas columnas pasan por la "provincia" que hostigaba a Villarrica y a la cual pertenecían los repartimientos del capitán Verdugo y Velmonte y Pedro Hernández de Córdova, entre otros. Las fuerzas rebeldes se habían acantonado en dos puntos extremos del lago; en Renigua y en Tepuco. Para llegar, a Renigua, punto defensivo principal de los alzados, los españoles debían atravesar el "desaguadero" (probablemente el río San Pedro), algunos en canoas. Renigua era un punto muy protegido a donde se accedía por un camino montuoso y difícil como lo señala Ruíz de Gamboa:

[...] pasamos por la más mala tierra de cordillera i quevradas por donde los subían y baxavan por escaleras i echas con sogas aderezamos tres leguas es este el camino más aspero que xamas e visto por donde aora a rienda suelta se puede caminar i comunicarse la ciudad de Baldivia con la ciudad rica i es de gran provecho para arar toda aquella cordillera nevada i pasarla donde es El maior golpe de la jente de guerra [...]" (AGI, Chile 31, Carta de Ruíz de Gamboa del 1 de abril de 1579, f. [3]).

En el pasaje anterior, Ruíz de Gamboa también menciona que este abrupto camino cordillerano podía servir de vía para comunicar Valdivia con Villarrica, lo que puede ser indicativo de rutas secundarias utilizadas en los desplazamientos requeridos por las faenas mineras o como sendas auxiliares en los conflictos hispano-indígenas.

\subsection{Los fuertes, marcas de territorios en disputa}

Algo destacable de la información de Ruíz de Gamboa, es que revela el uso de estructuras poliorcéticas por ambos bandos: por mapuche y españoles. También, el escrito da cuenta del uso ocasional y oportunista de algunas de estas fortalezas más bien improvisadas y sin mayores modificaciones humanas. En la Tabla 1 hemos ordenado cronológicamente los lugares defensivos que son mencionados en el documento.

La información de Ruíz de Gamboa evidencia que, a veintiséis años del ingreso de los españoles al Ngülümapu, los territorios que circundan las ciudades del sur, cuando no las ciudades mismas, eran espacios en disputa ${ }^{15}$. En efecto, si bien la población había sido distribuida desde la década de 1550 en encomiendas (Contreras 2017b, Jara 1987, Thayer 1911 y 1920) y los lavaderos de oro estaban en explotación, no se conseguía aún un control efectivo de toda la población ni de todos los espacios: rebeliones surgían aquí o allá, ofensivas militares incluían grupos de territorios fuera del control español, como por ejemplo los puelches cordilleranos. En este escenario, el control de los caminos y la mantención de las comunicaciones entre ciudades, entre estas y los puertos y de ambos tipos de urbes con los lavaderos de oro y las tierras de cultivo y pastoreo anexadas resultaba vital para la mantención del sistema de dominación hispano, de allí la importancia del uso de sitios y construcciones con características poliorcéticas.

El frágil y poco consolidado dominio territorial por parte de los españoles, explica la importancia del control de ciertos puntos estratégicos de las rutas y de las zonas de faenas mineras y agrícolas. Los denominados "fuertes" españoles fueron sin duda construcciones o lugares naturales modificados -en algunos casos, posiblemente sobre la base de antiguas construcciones indígenas- situados en etapas camineras o en promontorios de valles mineros o agrícolas, como el caso de Santa Sylvia cerca de Pucón (Gordon 1991 y 2011; Sauer 2012). Estos recintos, podían ser utilizados para el descanso y pernoctación de pasajeros y bestias, en otras ocasiones servían de refugios defensivos o como puntos de vigilancia y control de rutas, de faenas mineras y de campos de cultivo y pastoreo asociados a las ciudades. 
Tabla 1. Lugares defensivos señalados por Ruíz de Gamboa en su campaña militar al área lacustre del sur de la Araucanía, 1578-1579.

\begin{tabular}{|c|c|c|c|}
\hline Bando & Denominación & Localización & Informaciones señaladas \\
\hline Españoles & $\begin{array}{l}\text { Asiento en gran } \\
\text { llano }\end{array}$ & 3 leguas de Villarrica & $\begin{array}{l}1578 \text { (primavera). Asiento donde se acantona Gaspar } \\
\text { Verdugo, corregidor de Villarrica, con + de } 40 \text { soldados. } \\
\text { Es atacado una noche por indios rebeldes: } 3 \text { soldados } \\
\text { muertos y } 10 \text { heridos. }\end{array}$ \\
\hline $\begin{array}{l}\text { Españoles e Indios } \\
\text { Amigos }\end{array}$ & Frontera & 3 leguas de Villarrica & $\begin{array}{l}1578 \text { (primavera o principio verano). Frontera donde hay } \\
\text { un mulato con } 300 \text { indios amigos. Son atacados, Ruíz de } \\
\text { Gamboa (RdeG) envía refuerzos desde Villarrica: } 600 \\
\text { indios enemigos muertos. }\end{array}$ \\
\hline Indios Enemigos & Junta de Tерисо & $\begin{array}{l}\text { Tepuco, en un extremo } \\
\text { del lago Riñihue }\end{array}$ & $\begin{array}{l}\text { 1578-1579 (verano). Lugar de junta de indios enemigos. } \\
\text { Avanzada con } 200 \text { indios amigos lo atacan de noche } \\
\text { saliendo del campamento a } 8 \text { leguas de Renigua donde } \\
\text { se habían establecido las fuerzas de RdG: + de } 40 \text { indios } \\
\text { enemigos muertos y + de } 40 \text { capturados. }\end{array}$ \\
\hline Españoles & Fuerte & $\begin{array}{l}\text { Lago Riñihue, pasando el } \\
\text { desaguadero (lado sur?) }\end{array}$ & $\begin{array}{l}1578-1579 \text { (verano). Juan de Matienzo con una columna } \\
\text { de } 80 \text { soldados se refugian en un fuerte. }\end{array}$ \\
\hline Indios Enemigos & $\begin{array}{l}\text { Junta o fuerte de } \\
\text { Renigua }\end{array}$ & $\begin{array}{l}\text { Extremo del lago Riñihue, } \\
\text { pasando el desaguadero } \\
\text { (lado sur?), + de } 3 \text { leguas } \\
\text { de camino abrupto }\end{array}$ & $\begin{array}{l}1578-1579 \text { (verano). Fuerte en orilla de lago donde están } \\
\text { refugiados indios enemigos, acceso difícil entre quebradas } \\
\text { y cordilleras, el camino requiere ser despejado de la } \\
\text { vegetación. Las fuerzas españolas lo atacan: + } 90 \text { indios } \\
\text { enemigos muertos, estos piden tregua y entregan mozo } \\
\text { mestizo cautivo, se retiran del fuerte. Los españoles sufren } \\
13 \text { heridos ( } 10 \text { por puntas de proyectil envenenadas). }\end{array}$ \\
\hline Españoles & $\begin{array}{l}3 \text { fronteras con } \\
\text { buenos fuertes }\end{array}$ & Términos de Villarrica & $\begin{array}{l}1579 \text { (verano). RdeG deja } 3 \text { fronteras de españoles con } \\
\text { buena guarnición en buenos fuertes (uno ya existía). }\end{array}$ \\
\hline
\end{tabular}

Elaborado por JM Zavala. Fuente: AGI, Chile 31, Carta de Ruíz de Gamboa del 1 de abril de 1579, s./f.

\subsection{Guerra y lavaderos}

La relación de Ruíz de Gamboa muestra la realidad de una economía aurífera extractivista que opera en un clima social tenso e inestable donde acciones militares y actividades productivas conviven y se alternan en ambos campos: españoles y mestizos que un día son soldados y, al otro, mineros; indígenas que en una coyuntura ejercen como lavadores de oro y en otra como soldados auxiliares o combatientes rebeldes.

Esta realidad se evidencia claramente en la parte de la carta en que Ruíz de Gamboa le comenta al virrey el plan que había conversado con el gobernador del reino, Rodrigo de Quiroga, y en que destaca la abundancia del oro, pero al mismo tiempo la gran dificultad de su explotación, dice:

E tratado con el governador mi señor dos cosas: lo primero que pues los vecinos de las cinco ciudades Imperial Ciudad Rica
Baldivia Osorno Castro me davan de mil y trecientos indios amigos para arriba i estos forzosos se avían de ocupar en la guerra, los vecinos destas ciudades dichas diesen los quatro años dellos pa sacar oro en la imperial y a gastos de guerra y fuese en la Imperial, donde se an descubierto muy rricas minas que ogaño con grande dificultad por las guerras que allá e tenido todavía sacaron más de sesenta myll pesos sin lo que los indios hurtaron y ansi mysmo en las otras ciudades se a sacado lo ordinario que con toda la guerra que e tenido siempre, con todo eso hize alto pa que en todas estas ciudades sacasen oro, que es El sustento de la tierra. La Imperial es el principio de la guerra principal i haciendo esto los vecinos haga el governador mi señor hacer un fuerte $y$ hacer alto sobre las minas, que en efecto son muy rricas y en muchas partes y desde allí haciendo 
este efecto salga capitán a hacer la guerra a las provincias de Purén Tucapel Arauco Mareguano y Coyuncos, por manera que del travajo bamos sacando fruto i que a esta riqueza vengan con sus quadrillas a sacar oro de todas las ciudades de arriba, demás desto ai otro Efecto bueno en esto que En hacer alto en estas minas hacen espaldas a lo de los indios alterados de las ciudades de arriba (AGI, Chile 31, Carta de Ruíz de Gamboa del 1 de abril de 1579, f. [5]. [El destacado es nuestro]).

Entre las propuestas que hace Ruíz de Gamboa al virrey Toledo, cabe destacar la referente a que se permitiera a los soldados españoles destinar las "piezas" capturadas (los cautivos de guerra) al laboreo minero para su beneficio personal, reservando algunos como soldados, dice:

Asimismo e tratado con el governador mi señor que mande que todos los soldados que anduvieren en el campo en la pacificacion de la tierra, todos los indios e indias que tomasen sean suios y tratar que las quadrillas todas que entraren en estas minas, porque los soldados hagan alto, sean obligados por cada cinquenta cavadores sustentar cinco u seis piezas de soldados para que en tomando los soldados algunas piezas pueda el governador mi señor mandar a fulano que los sustente y saquen oro pa El soldado. Todo esto esta vien a los vecinos, porque las minas son rricas y les será de mayor fructo y no haciéndolo cesaría El sacar oro y de esta manera El vien a todos (AGI, Chile 31, Carta de Ruíz de Gamboa del 1 de abril de 1579, f. [6]). [El destacado es nuestro]

El pasaje anterior nos habla de una economía en que guerra y explotación aurífera van de la mano y donde pareciera que la encomienda como principal institución de este sistema de conquista no basta por sí sola para garantizar la explotación de los lavaderos de oro y el control de la población indígena. La petición del futuro gobernador del reino de Chile es que no solo los señores encomenderos se beneficien de las explotaciones auríferas sino también los soldados y que no solo los indígenas encomendados trabajen en ellas sino también los cautivos de guerra convertidos en esclavos.

\section{Conclusión}

Hemos podido constatar que durante el siglo XVI tuvieron plena vigencia en el Ngülümapu dos instituciones fundamentales del sistema colonial español: las ciudades y las encomiendas. Estos dos pilares del modelo colonizador hispano pudieron concretarse porque existían ya condiciones previas para su desarrollo: un sistema de vías de comunicación terrestre operativo y comunidades locales numerosas, productivas y organizadas que podían proporcionar la mano de obra y la producción necesarias para la sustentación de los enclaves españoles y el funcionamiento de una economía extractivista del oro.

Dicho esto, como nos muestra el informe de Ruíz de Gamboa, se trataba de un sistema frágil e inestable donde no estaba garantizado plenamente su funcionamiento y que generaba mucha resistencia. No existía un control territorial pleno, por ello las vías de comunicación, los enclaves urbanos y los puestos poliorcéticos se convertían en espacios estratégicos que podían cambiar de manos entre conquistadores y rebeldes.

La actividad económica no podía operar sin lo militar, ello hacía que hubiera una suerte de imbricación y conjunción de intereses entre economía de guerra y economía aurífera donde encomenderos, soldados y criados (hijosdalgo, plebeyos, mestizos, mulatos y negros) asumían la dirección de las faenas mineras y los indígenas encomendados junto con otros capturados en la guerra (fueran hombres, mujeres o niños) el laboreo en los lavaderos.

\section{Agradecimientos}

Nuestros agradecimientos a CONICYTFONDECYT por el financiamiento otorgado a esta investigación a través del proyecto Fondecyt Regular $\mathrm{N}^{\circ} 1170551$, al Consejo de Monumentos Nacionales que ha dado seguimientos a los trabajos arqueológicos y a la Universidad Católica de Temuco y Universidad de Chile, sus patrocinadores. Por otra parte, agradecemos grandemente a los habitantes y estudiosos de las comunas de 
Angol, Arauco, Cañete, Carahue, Hualqui, Pucón, Purén, San José de la Mariquina, Temuco y Villarrica por los permisos e informaciones aportadas. Finalmente, agradecemos a los evaluadores de este artículo por su valioso tiempo e invaluables recomendaciones.

\section{Referencias Citadas}

Adán, L.; Mera, R..; Bahamondes F. y S. Donoso

2007 "Historia cultural de la cuenca del rio Valdivia: Proposiciones a partir del estudio de sitios alfareros prehispánicos e históricos". Revista Austral de Ciencias Sociales, 12:5-30.

Adán, L.; Urbina, S.; Lira, N.; Mera, R.; Munita, D. y V. Figueroa

2012 Registro y caracterización básica de los recursos arqueológicos del lago Ranco, Región de Los Ríos. Actas del XIX Congreso Nacional De Arqueología Chilena, pp. 497-505.

Adán, L.

2014 Los Reche-Mapuche a través de su sistema de asentamiento (S. XV-XVII). Tesis para optar al grado de Doctora en Historia, Universidad de Chile, Santiago.

Antileo, E.; Cárcamo-Huechante, L.; Calfío, M. y H. HuincaPiutrin (Editores)

2015 Violencias coloniales en el Wajmapu. Awükan ka kuxunkan zugu Wajmapu meu. Piutrin Editores, Santiago.

Comunidad de Historia Mapuche

2013 Ta in fijke xipa rakizuameluwun. Historia colonialismo y resistencia desde el país mapuche. Comunidad de Historia Mapuche, Santiago.

Contreras, $\mathrm{H}$.

2016 "Migraciones locales y asentamiento indígena en las estancias españolas de Chile Cenral, 1580-1650". Historia, 49: 87-110.

Contreras, $\mathrm{H}$.

2017a Oro, tierras e indios: encomienda y servicio personal entre las comunidades indígenas de Chile Central, 1541-1580. Ediciones Universidad Academia de Humanismo Cristiano, Santiago.

Contreras, $\mathrm{H}$.

2017b "Indios de Tierra adentro en Chile Central: las modalidades de la migración forzosa y el desarraigo (fines del siglo XI y comienzos del XVII)". Jaime Valenzuela (ed.), América en diásporas. Esclavitud y migraciones forzadas en Chile y otras regiones americanas (siglos XVI-XVII), pp. 161-196. RIL Editores, Santiago.

Contreras, $\mathrm{H}$.

2018 "Viviendo entre cristianos como gentiles y entre españoles como bárbaros. Borracheras indígenas, doctrina cristiana y migración forzada en Chile Central, 15751655". Revista Complutense de Historia de América, 44: 87-109.

Cuadra, W y M. Arenas

2001 El Oro de Chile. Desde los Tiempos Prehispánicos (900 a.C.) Hasta Nuestra Independencia (1810), Tomo 1, Lom, Santiago.

Góngora Marmolejo, A.

1862 [1575] Historia de Chile Desde su Descubrimiento Hasta el Año de 1575, Colección de Historiadores de Chile, Tomo 2. Imprenta del Ferrocarril, Santiago.
Gordon, A.

1985 Un fortín español en la época temprana de la conquista. Carilafquén, comuna de Pitrufquén, IX Región. I Congreso Chileno de Antropología. Colegio de Antropólogos de Chile A.G, Santiago de Chile, pp. 540-551.

Gordon, A.

1991 La Casa Fuerte de Santa Sylvia. Excavación de Sondeo. Actas del XI Congreso Nacional de Arqueología Chilena, Tomo III. Museo Nacional de Historia Natural / Sociedad Chilena de Arqueología, Santiago.

Gordon, A

2011 Excavación de la Residencia Fortificada de un Encomendero Español: La Casa Fuerte Santa Sylvia, Villa San Pedro, Pucón. Informe Técnico de 1992-1993, Vanderbilt University Publications in Anthropology, Nashville.

Guarda, G.

1978 Historia Urbana del Reino de Chile, Editorial Andrés Bello, Santiago.

Guarda, G.

1990 Flandes Indiano: Las Fortificaciones del Reino de Chile, 1541-1826. Ediciones Universidad Católica de Chile, Santiago.

Harcha, L.; Lucero, V.; Mera, R. y L. Vásquez.

1999 "Visión etnohistórica arqueológica de asentamientos urbanos y militares del temprano contacto hispano indígena”. Soñando el Sur 2:133-148.

Inostroza, I.

1994 La población mapuche de Araucanía y el fuerte español de Boroa (1640-1650). Notas Históricas y Geográficas, 5-6: 145-166.

Inostroza, I.

2013 "La colonización minera y agrícola en la ciudad Imperial del Sur de Chile: 1551-1561". Revista Complutense de Historia 39:107-127.

Inostroza, I.

2014 Las aldeas fortificadas mapuche y el tráfico minero indígena entre Araucanía y Neuquén, 1550-1560. Universidad de la Frontera, Temuco (manuscrito en posesión del autor).

Inostroza, I.; Saavedra, J. y C. Rodríguez

2017 Historia y Arqueología de Carahue- La ciudad Imperial y la sociedad mapuche del siglo XVI. Municipalidad de Carahue.

Jara, A.

1987 Trabajo y salario indígena a en el siglo XVI. Editorial Universitaria, Santiago.

Keeley, L. H.

1996 War Before Civilization, Oxford University Press, New York.

Krumm, G.

1974 "Localización geográfica de algunos fuertes hispano-coloniales en Chile". Revista Geográfica de Chile 22-23:201-216. 
León, L.

1986 "La resistencia anti-española y el rol de las fortalezas indígenas en Chile Central, 1536-1545". Sociedad, Hombre y Cultura (CUHSO) 3(1):53-116.

León, L.

1988-1989 "La alianza puelche-huilliche y las fortificaciones indígenas de Libén, Riñihue y Villarrica, 1552-1583", Nueva Historia 17: 13-46.

León, L.

1990 Maloqueros y Conchavadores en Araucanía y las Pampas, 1700-1800. Ediciones Universidad de la Frontera, Santiago.

Marimán, P.; Caniuqueo, S.; Millalén, J. y R. Levil

2006 i...Escucha, winka...! Cuatro ensayos de Historia Nacional Mapuche y un epilogo sobre el futuro. Lom Editores, Santiago,

Mariño de Lovera, P.

1865 [1595] Crónica del reino de Chile. Colección de Historiadores de Chile, Tomo 6. Imprenta del Ferrocarril, Santiago.

Medina, J.T.

1888-1902 Colección de Documentos Inéditos para la Historia de Chile. Primera Serie. Imprentas Ercilla, Barcelona y Elzeviriana.

Medina, J.T.

1956-1963 Colección de Documentos Inéditos para la Historia de Chile. Segunda Serie. Fondo Histórico y Bibliográfico J. T. Medina.

Mera, R.; Lucero, V.; Vásquez, L.; Harcha, L. y V. Reyes

2004 "Sitios históricos tempranos de carácter defensivo. Sector oriental de la Villa Rica (1550-1602)". Chungara 36 supl.espec. t.1:175-186.

Mera, R., Reyes, V. y L. Vásquez

2007 Reevaluación del sitio Casa Fuerte Santa Sylvia (IX Región-Chile). VI Congreso Chileno de Antropología, Colegio de Antropólogos de Chile A.G, Valdivia, pp. 1947-1957.

Mera, M.; Munita, D.; Urbina, S.; Ibacache, S. y X. Navarro

2015 Ocupación estratégica de la Villa Rica y la importancia del río Toltén. Actas del XIX Congreso Nacional de Arqueología Chilena 2012, Santiago, pp. 349-353.

Mrakic, A.

2013 El Desarrollo del Conocimiento Constructivo Militar Desde Vitruvio Hasta el Siglo XVII. Tesis doctoral, Universitat Politécnica de Valéncia, España.

Obregón, J.

2008 "Concepciones hispanas en torno a un territorio disputado, araucano mapuches y españoles durante el siglo XVII, Chile". Cultura y representaciones sociales. Un espacio para el diálogo transdisciplinario 2 (4): 94-107.

Palacios, A.

2016 Fuentes para la Historia Sísmica de Chile (15701906). Centro Diego Barros Arana/DIBAM, Santiago.

Palacios, S.

2019 "Cómo defender la frontera. Reflexiones sobre estrategias territoriales y poliorcética en el mundo hispano medieval". Intus - Legere Historia 13(1):3-36.

Reyes, V.

2004 "Relaciones interétnicas en asentamientos del siglo XVI de la precordillera lacustre, IX y X regiones: análisis cerámico". Chungara, volumen especial: 161-174.
Ruíz de Gamboa, M.

1957 [1579] "Carta de Martín Ruíz de Gamboa al virrey del Perú sobre la guerra de Arauco". Colección de Documentos Inéditos para la Historia de Chile, segunda serie, tomo 2, pp. 390-397. Fondo Histórico y Bibliográfico J. T. Medina, Santiago.

Rosales, D.

1878 [1674] Historia General de el Reyno de Chile, Flandes Indiano. Edición de Benjamín Vicuña Mackenna, Imprenta del Mercurio, Valparaíso.

Saavedra, J. y Sanzana, P.

1991 Introducción al estudio de fortificaciones tempranas en el Valle del Toltén y Precordillera de Villarrica (Frontera Sur del Estado de Arauco). Master's thesis, Universidad Austral, Chile.

Sánchez, M.

2012 "La fortificación y el arte militar en los tratados renacentistas: estudio lexicográfico". Cuadernos del Instituto Historia de la Lengua 3: 225-232, Universidad de Salamanca, España.

Sauer, J.

2012 Long-term resilience in cultural systems: An Araucanian example from Santa Sylvia, South-Central Chile. Tesis Doctoral, Universidad de Vanderbilt, Nashville, Tennessee, EE.UU.

Thayer, T.

1911 "Las antiguas ciudades de Chile". Anales de la Universidad de Chile 129: 169-216.

Thayer, T.

1920 Apuntes para la historia económica y social durante el período de la conquista de Chile, 1540-1565. Imprenta Universitaria, Santiago.

Urbina, S. y L. Adán

2014. "Avances en la arqueología de Valdivia". Boletín de la Sociedad Chilena de Arqueología 43-44: 35-60.

Urbina, S. y L. Adán

2018 "Formaciones urbanas coloniales: Historia ocupacional de Valdivia a través de la cerámica (Siglos XV-XIX)". Revista de Arqueología Histórica Argentina y Latinoamericana 12:141-173.

Valenzuela. J.

2017 América en diásporas. Esclavitud y migraciones forzadas en Chile y otras regiones americanas (siglos XVI-XVII). RIL Editores, Santiago.

Vidal, A.; Saavedra, J.; Sanzana, P. y L. Harcha.

1986 "Fortificaciones hispanas en el valle del Toltén". Sociedad, Hombre y Cultura (CUHSO) 3(2): 337-347.

Vivar, J.

Crónica y relación copiosa y verdadera de los reynos de Chile hecha por Gerónimo de Bibar. Fondo histórico y bibliográfico José Toribio Medina, 1966 [1558], Santiago.

Zavala, J.M.

2010 “Enemigos o rebeldes?, categorización hispana de la resistencia mapuche en el Chile del Siglo XVIII". En América Colonial: Denominaciones, Clasificaciones e Identidades, A. Araya y J. Valenzuela (editores), pp. 201217. RIL Editores, Santiago.

Zavala, J. M. y Dillehay, T.

2010 "El 'Estado de Arauco' frente a la conquista española: estructuración sociopolítica y ritual de los 
araucano-mapuches en los valles nahuelbutanos durante los siglos XVI y XVII”. Chungara 42-2: 433-450.

Zavala, J. M.; Medianero, F. y Dillehay, T.

[2020] "La actividad aurífera en el sur de Chile durante el siglo XVI: primeras aproximaciones arqueo-históricas". En Roberto Lleras Pérez y Luisa María Vetter (eds.), Los Metales en nuestra historia. Lima: IFEA (en prensa).

\section{Fuentes}

Archivo General de Indias, Sevilla (AGI).

Audiencia de Chile (Chile), legs. 31 y 40.

Contaduría, leg. 1851.

Patronato, legs. 29 y 187.

Archivo Histórico Nacional de Chile, Santiago (AHNCh). Manuscritos Vicuña Mackenna (MVM), vols. 273 y 274.

Notas

1 Las estructuras poliorcéticas representan entidades edilicias fuertemente muradas o construcciones con planimetrías que denotan un esfuerzo y trabajo humano cuya funcionalidad y resultado se enmarca en ingeniería militar. De interés nos resultan sobre esta materia, la reciente publicación de S. Palacios, 2019 y las tesis doctorales de M. Sánchez, 2012 y A. Mrakic, 2013.

2 Para el siglo XVI, entendemos por Araucanía o Ngülümapu en mapudungun, el territorio situado a grandes rasgos del río Biobío al sur, entre los Andes y el océano Pacífico, incluida la jurisdicción de la ciudad de Valdivia. Luego de su refundación en 1647, Valdivia y el territorio bajo su dependencia se ligará cada vez menos a Concepción, comenzando a marcarse así una frontera en las dinámicas sociopolíticas en torno al río Toltén.

3 En el original que analizamos aquí (AGI, Ch.31, Carta de Juan Ruíz de Gamboa al virrey del Perú del 1 de abril de 1579, 7 fojas no numeradas.) quien firma el documento figura con el nombre "Juan" y no "Martín", hemos buscado en otros documentos y referencias para saber si el nombre "Juan" aparece asociado a Martín Ruíz de Gamboa, pero sin resultados positivos. En todo caso, estamos seguro que "Juan" Ruíz de Gamboa y "Martín" Ruíz de Gamboa son una misma persona. Por lo demás, José Toribio Medina trascribió una copia exacta de esta carta desde el Archivo General de Indias de Sevilla, publicada posteriormente en la C.D.I.H.Ch., y el nombre de pila con que figura allí quien la escribe es "Martín" (Ruíz de Gamboa, 1957 [1579]: 390-397).

4 En un trabajo presentado en el $56^{\circ}$ Congreso de Americanistas de Salamanca pronto a publicarse como capítulo de libro (Zavala et al., [2020]), tratamos en específico la contribución de los lavaderos de La Araucanía a la productividad del oro chileno.

5 En este caso estaría por ejemplo el fuerte de Quilacoya que, según Góngora Marmolejo, Pedro Valdivia mandó fundar "para seguridad de los españoles que en las minas andaban (Góngora Marmolejo, 1862 [1575]: 33).

6 Yanaconas se denominó primitivamente en Chile a los indígenas que los españoles trajeron del Tawantinsuyu en sus expediciones de conquista, pero igualmente se podía cafificar de ese modo a los mitimaes ya establecidos en suelo chileno bajo la dominación inca. En ambos casos, los españoles los incorporaron a su servicio y fuerzas.
Con el tiempo, el término tiende a generalizarse para designar a cualquier indígena desplazado e incorporado a las huestes españolas.

7 En el siglo XVI chileno, se denominó ciudades de "arriba" a las que quedaban al sur del río Biobío, es decir: Angol, Cañete, Imperial, Villarrica, Valdivia, Osorno y Castro.

8 De sur a norte, los principales puertos de virreinato del Perú a los cuales debían conectarse los territorios recién conquistados, eran: Concepción, Valparaíso (puerto de Santiago); Coquimbo (puerto de La Serena) y el Callao (puerto de Lima).

9 Por razones de espacio no nos es posible detallar aquí los itinerarios de estos primeros viajes (Góngora Marmolejo 1862 [1575]: 25, 28-29, 33; Thayer 1911: 849).

10 La perspectiva de Leonardo León tiende más bien a explicar los acontecimientos en tanto estrategias políticas intencionales de los actores, nosotros buscamos preferentemente entender los procesos y tendencias que se delinean tras dichos acontecimientos.

11 Para más detalle sobre los Levo y la estructura sociopolítica mapuche del siglo XVI ver Zavala y Dillehay, 2010.

12 Sobre el tema de las categorías indios "amigos" y "enemigos" ver Zavala, 2010.

13 En el río Liucura, está el sitio arqueológico del siglo XVI denominado Casa Fuerte Santa Silvia, donde se han encontrado evidencias de actividad aurífera (Gordon 1985, 2011; Sauer, 2012).

14 Entendemos que se trata del lago Riñihue, tanto por los datos geográficos que da la relación como por el nombre de "Renigua" (castellanización del término mapuche reniwue) y que debió ser una variante léxica inicial que derivó posteriormente en Riñihue. Además, las fuentes sobre el terremoto de 1575 señalan que entre los efectos del sismo se produjo un "tapón" del desaguadero de este lago que meses después explotó, ver al respecto la documentación publicada por Alfredo Palacios (2016: 32-40). Por otra parte, Leonardo León también entiende en su trabajo que se trata de Riñihue (León, 1988-1989: 35).

15 Esta situación de territorio en disputa se resolverá en favor de los mapuche a partir de la rebelión de 1598-1602, posteriormente las tentativas españolas de reocupación no darán los frutos esperados; ver al respecto el análisis de Jimena Obregón (2008). 